\title{
A MODEL FOR EVALUATING THE FIRE RESISTANCE OF HIGH PERFORMANCE CONCRETE COLUMNS
}

\author{
V.K.R Kodur ${ }^{1}$, T.C. Wang ${ }^{2}$, F.P. Cheng ${ }^{2}$ and M.A. Sultan ${ }^{1}$ \\ ${ }^{1}$ National Research Council, Ottawa, Canada. E-mail: Venkatesh.kodur@nrc.ca \\ ${ }^{2}$ Department of Civil Engineering, National Chiao Tung University, HsinChu, Taiwan.
}

\begin{abstract}
A numerical model, in the form of a computer program, for evaluating the fire resistance of high performance concrete (HPC) columns is presented. The three stages, associated with the thermal and structural analysis, for the calculation of fire resistance of columns is explained. A simplified approach is proposed to account for spalling under fire conditions. The use of the computer program for tracing the response of an HPC column from the initial pre-loading stage to collapse, due to fire, is demonstrated.
\end{abstract}

The validity of the numerical model used in the program is established by comparing the predictions from the computer program with results from full-scale fire resistance tests. Details of fire resistance experiments carried out on HPC columns, together with results, are presented. The computer program can be used to evaluate the fire resistance of HPC columns for any value of the significant parameters, such as load, section dimensions, fiber reinforcement, column length, concrete strength, aggregate type, and fiber reinforcement without the necessity of testing.

KEYWORDS: Fire resistance, computer program, high performance concrete columns, spalling, numerical model

\section{INTRODUCTION}

In recent years, the construction industry has shown significant interest in the use of high performance concrete (HPC). This is due to improvements in structural performance, such as high strength and durability, that it can provide compared to traditional, normal strength concrete (NSC). Generally, concrete up to a compressive strength of $55 \mathrm{MPa}$ is referred to as normal strength concrete (NSC), while concrete with compressive strength in excess of $55 \mathrm{MPa}$ is classified as high strength concrete (HSC). HPC is typically characterized by high strength, good workability and durability and HSC is a subset of HPC.

One of the major uses of HPC in buildings is for reinforced concrete (RC) columns. The columns form the main load bearing components in a building and hence, the provision of appropriate fire safety measures is one of the major safety requirements in building design [1]. However, there are no guidelines for the fire resistance design of RC columns made of HPC $[2,3]$.

Further, results of fire tests in a number of laboratories have shown that there are welldefined differences between the properties of HSC and NSC at elevated temperatures $[4,5]$. Also, concern has developed regarding the occurrence of explosive spalling when HSC is subjected to rapid heating, as in the case of a fire $[4,5,6,7]$. Spalling is theorized to be caused by the build-up of pore pressure during heating $[4,8]$. HSC is believed to be 
more susceptible to this pressure build-up because of its low permeability compared to NSC. The extremely high water vapor pressure, generated during exposure to fire, cannot escape due to the high density of HSC and this pressure often reaches the saturation vapor pressure. At $300^{\circ} \mathrm{C}$, the pressure reaches about $8 \mathrm{MPa}$. Such internal pressures are often too high to be resisted by the HSC mix having a tensile strength of about $5 \mathrm{MPa}$ [4]. Data from various studies show that predicting fire performance of HSC, in general, and spalling, in particular, is very complex since it is affected by a number of factors $[4,5,8]$.

Recent developments, including the development of numerical techniques and an enhanced knowledge of the thermal and mechanical properties of materials at elevated temperatures, have made it possible to determine the fire resistance of various structural members by calculation. A detailed literature review revealed that whereas the computer models have been established for determining the fire resistance NSC columns, this is not the case with HPC columns [6,7]. Further, there is only limited test data available on the fire resistance of HPC columns [5,7].

To develop guidelines for the fire resistant design and construction of HPC columns, a collaborative research project was undertaken between National Research Council of Canada (NRCC) and National Chiao Tung University (NCTU), Taiwan. Both experimental and theoretical studies were carried out to investigate the fire performance of HPC columns.

In this paper, a numerical model in the form of a computer program, for evaluating the fire resistance of high performance concrete (HPC) columns, is presented. Spalling of HSC, under fire conditions, is accounted for in the model thorough a simplified approach. Results of experiments are used to trace the structural behavior of HPC concrete columns at elevated temperatures. The validity of the numerical model used in the program is established by comparing the predictions from the computer program with results from full-scale fire resistance tests.

\section{EXPERIMENTAL STUDIES}

\section{Test Specimens}

The experimental study consisted of conducting fire resistance tests on four reinforced concrete columns, namely THC4, THC8, THS11 and THP14, made of HPC. All columns were $3810 \mathrm{~mm}$ long and of a square cross-section of $305 \mathrm{~mm}$. The dimensions of the column cross-section and other specifics of the columns are given in Table 1.

The columns were designed as per ACI specifications [3]. All columns had four, $25 \mathrm{~mm}$, longitudinal bars. The bars were tied with $10 \mathrm{~mm}$ ties at a spacing of $75 \mathrm{~mm}$ in both ends and $145 \mathrm{~mm}$ in the middle. The main reinforcing bars and ties had a specified yield strength of $420 \mathrm{MPa}$ and $280 \mathrm{MPa}$, respectively. Figure 1 shows the elevation and crosssectional details of the columns together with the locations of the ties.

Four batches of concrete were used in fabricating the columns. Steel and polypropylene fibers reinforcement were added to Batch 3 and Batch 4, respectively. The coarse aggregate in Batch 2 was of carbonate type, while the other batches were made with siliceous aggregate. Columns THC4, THC8, THS11 and THP14 were fabricated from 
Batch 1, Batch 2, Batch 3 and Batch 4, respectively. All four batches of concrete were made with general purpose Type 1 Portland cement.

Table 1 - Summary of Test Parameters and Results for HPC Columns

\begin{tabular}{|c|c|c|c|c|c|c|c|c|}
\hline \multirow[t]{2}{*}{ Column } & \multirow[t]{2}{*}{$\begin{array}{c}\text { Column } \\
\text { Dimensi- } \\
\text { ons }\end{array}$} & \multicolumn{2}{|c|}{$\begin{array}{l}\text { Concrete } \\
\text { Strength } \\
\left(f^{\prime} c\right)\end{array}$} & \multirow{2}{*}{$\begin{array}{c}\text { Factored } \\
\text { Resistance } \\
(\mathrm{Cr}) \\
\mathrm{kN}\end{array}$} & \multirow{2}{*}{$\begin{array}{c}\text { Test } \\
\text { Load (C) } \\
\\
\mathrm{kN}\end{array}$} & \multirow{2}{*}{$\begin{array}{c}\text { Load } \\
\text { Intensity } \\
\mathrm{C} / \mathrm{Cr}\end{array}$} & \multicolumn{2}{|c|}{ Fire Resistance } \\
\hline & & $\begin{array}{c}28 \\
\text { day } \\
\mathrm{MPa}\end{array}$ & $\begin{array}{l}\text { test } \\
\text { day } \\
\mathrm{MPa}\end{array}$ & & & & $\begin{array}{c}\text { Test } \\
\text { h:min }\end{array}$ & $\begin{array}{l}\text { Model } \\
\text { h:min }\end{array}$ \\
\hline THC4 & $305 \times 305$ & 60.6 & 99.6 & 3697 & 2000 & 0.54 & $3: 22$ & $3: 06$ \\
\hline THC8 & $305 \times 305$ & 60.4 & 72.7 & 2805 & 2000 & 0.71 & $5: 05$ & $4: 31$ \\
\hline THS11* & $305 \times 305$ & 63.2 & 89.1 & 3349 & 2200 & 0.66 & $3: 26$ & $2: 56$ \\
\hline THP14** & $305 \times 305$ & 51.9 & 86.8 & 3266 & 2200 & 0.67 & $3: 53$ & 3:03 \\
\hline
\end{tabular}

$\begin{array}{lll}{ }^{*} \text { Contained steel fibers } & { }^{* *} \text { Contained polypropylene fibers } & { }^{+} \text {Calculated as per CSA [2] }\end{array}$

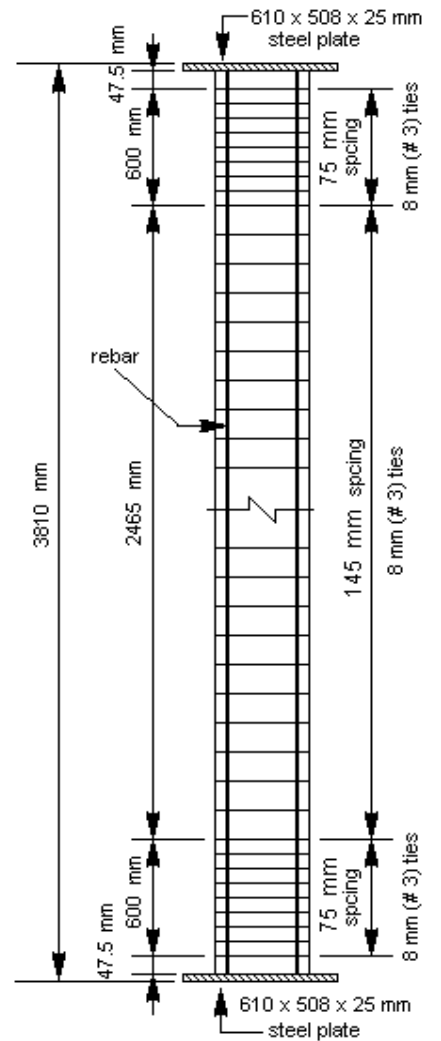

(a) Elevation
The average compressive cylinder strength of the concrete, measured 28 days after pouring and on the day of the testing, are given in Table 1. The moisture condition at the center of the column was also measured on the day of the test using Vaisala moisture sensor.. The moisture conditions of Columns THC4, THC8, THS11 and THP14 are approximately equivalent to those in equilibrium with air of $78 \%$, $67 \%, 99 \%$ and $85 \%$ relative humidity, respectively, at room temperature.

Type-K Chromel-alumel thermocouples, $0.91 \mathrm{~mm}$ thick, were installed at mid-height in the columns for measuring concrete and rebar temperatures at different locations in the cross-section. Full details on the design and fabrication of columns are given in Reference 7.

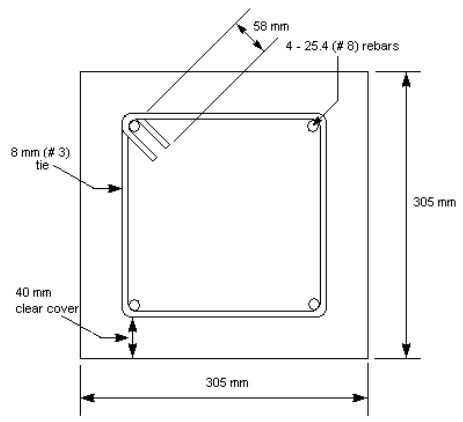

(b) Cross section

Figure 1 Elevation and cross-section of reinforced concrete columns 


\section{Test Apparatus}

The tests were carried out by exposing the columns to heat in a furnace specially built for testing loaded columns. The furnace consists of a steel framework supported by four steel columns, with the furnace chamber inside the framework. The test furnace was designed to produce conditions, such as temperature, structural loads and heat transfer, to which a member might be exposed during a fire. The furnace has a loading capacity of $1,000 \mathrm{t}$. Full details on the characteristics and instrumentation of the column furnace are provided in Reference 9.

\section{Test Conditions and Procedure}

The columns were installed in the furnace by bolting the endplates to a loading head at the top and to a hydraulic jack at the bottom. The end conditions of the columns were fixed-fixed for all tests. For each column, the length exposed to fire was approximately $3000 \mathrm{~mm}$. At high temperature, the stiffness of the unheated column ends, which is high in comparison to that of the heated portion of the column, contributes to a reduction in the column effective length. In previous studies, it was found that, for columns tested fixed at the ends, an effective length of $2000 \mathrm{~mm}$ represents experimental behavior [10].

All columns were tested under concentric loads. Column THC4 was subjected to a load of $2000 \mathrm{kN}$, which is equal to $54 \%$ of the ultimate load according to ACI318 [3]. Column THC8 was subjected to a load of $2000 \mathrm{kN}$ or $71 \%$ of the ultimate load, column THS 11 to a load of $2200 \mathrm{kN}$ or $66 \%$ of the ultimate load, and column THP14 to a load of $2200 \mathrm{kN}$ or $67 \%$ of the ultimate load. The load intensity, defined as the ratio of the applied load to the column resistance (factored or ultimate load) for the various columns is given in Table 1.

The load was applied approximately $45 \mathrm{~min}$ before the start of the fire test and was maintained until a condition was reached at which no further increase of the axial deformation could be measured. This was selected as the initial condition for the axial deformation of the column. During the test, the column was exposed to heat, controlled in such a way that the average temperature in the furnace followed, as closely as possible, the ASTM E119-88 [11] or CAN/ULC-S101 [12] standard temperature-time curve. The load was maintained constant throughout the test. The columns were considered to have failed and the tests were terminated when the hydraulic jack, which has a maximum speed of $76 \mathrm{~mm} / \mathrm{min}$, could no longer maintain the load.

The main results from the experimental studies, aimed at validating the computer model, are presented in the following sections. Detailed results from the experimental studies, including measured temperatures and deflections, are discussed in Reference 7.

\section{NUMERICAL MODEL}

\section{Description of the Model}

A numerical model for predicting the behavior of HPC columns, exposed to fire, was developed as part of this study. The numerical procedure used in the model is similar to the one which was previously applied to the fire resistance calculations of NSC columns $[13,14]$. 
The fire resistance calculation is performed in three steps; namely, the calculation of the temperatures of the fire to which the column is exposed, the calculation of the temperatures in the column, and the calculation of the resulting deformations and strength, including an analysis of the stress and strain distribution. In the strength analysis calculations, the extent of spalling is accounted for through a simplified approach. Detailed equations for the calculation of the column temperatures and strength are given in References 13 and 14.

\section{Fire Temperature}

In the numerical model, it is assumed that the entire surface area of the column is exposed to the heat of a fire, whose temperature follows that of the standard fire exposure described in ASTM E119-88 [11] or CAN/ULC S101 [12]. This temperature course can be approximated by the following expression:

$$
\mathrm{T}_{\mathrm{f}}=20+750[1-\exp (-3.79553 \sqrt{\tau})]+170.41 \sqrt{\tau}
$$

where $\tau$ is the time in hours and $\mathrm{T}_{\mathrm{f}}$ is the fire temperature in ${ }^{\circ} \mathrm{C}$ at time $\tau$.

\section{Temperatures in Column}

The column temperatures are calculated by a finite difference method [15]. Figure 1 shows the elevation and cross-sectional details of a typical RC column. The crosssectional area of the column is subdivided into a number of elements, arranged in a triangular network. The elements are square inside the column and triangular at the column surface. For the inside elements, the temperature at the centre is taken as representative of the entire element. For the triangular surface elements, the representative points are located on the centre of each hypotenuse.

For reasons of symmetry, only one-quarter of the section needs to be considered when calculating the temperature distribution in columns with a rectangular cross-section. The temperature rise in the column can be derived by creating a heat balance for each element. The calculations were carried out for a unit length of the column.

The effect of moisture is taken into account by assuming that, in each element, the moisture starts to evaporate when the temperature of the element reaches $100^{\circ} \mathrm{C}$. During the period of evaporation, all the heat supplied to an element is used for the evaporation of the moisture until the element is dry.

\section{Strength of Column}

In order to calculate the strains and stresses in the column and its strength during fire exposure, the triangular network described above is transformed into a square network [14]. The temperatures, deformations and stresses in each element are represented by those at the centre of the element. The temperature at the centre of each element is obtained by averaging the temperatures of the elements in the triangular network noted above.

For the steel reinforcing bars, an approximate average bar temperature is obtained by considering the column as consisting entirely of concrete and selecting the temperature at the center of the bar section as the representative bar temperature. Temperature 
measurements at various locations during fire tests showed that the difference in temperature in the bar and sections are small [13].

The strain in an element of concrete can be given as the sum of the thermal expansion of the concrete, the axial strain due to compression and the strain due to bending of the column. A similar calculation is performed for the steel reinforcing bar elements. The stresses at mid-section in the concrete elements can be calculated for any value of the axial strain, $\varepsilon$, and curvature, $1 / \rho$. From these stresses, the load that each element carries and its contribution to the internal moment at mid-section can be determined. By adding the loads and moments, the load that the column carries and the total internal moment at mid-section can be calculated. Detailed equations for strength calculation are derived in References 13 and 14.

The fire resistance of the column is derived by calculating the strength, i.e., the maximum load that the column can carry, at several consecutive times during the exposure to fire.

\section{Extent of Spalling}

Spalling of concrete under fire conditions is one of the major concerns in HSC and should be accounted for modeling the behavior of HSC columns exposed to fire. Spalling is a complex phenomenon and there is still a debate on the exact mechanism for the occurrence of spalling [8]. Data from various studies show that spalling in HSC is affected by concrete strength, concrete density, load intensity and type, moisture content, tie configuration, fire intensity, aggregate type, addition of fibers and specimen dimensions [8]. For accurate modeling of spalling, pore pressure-temperature relationship is required. However, such data is not available at present. Hence a simplified approach is used in order to minimize the complexity of the model and to facilitate easy usage of the computer program.

Based on detailed experimental studies on HSC columns, it was found that spalling occurs when temperatures in concrete reach above $350^{\circ} \mathrm{C}$ [7]. During fire resistance tests it was observed that at about 15 minutes the temperatures close to the column surface (at depths much less than $19.5 \mathrm{~mm}$ ) reaches $350^{\circ} \mathrm{C}$, and spalling is likely to occur in this zone. At about 30 minutes the spalling zone spreads to about $19.5 \mathrm{~mm}$ from surface. Data from the experimental studies also showed that, while spalling occurs throughout the cross-section in the case of columns with straight ties, spalling occurs only outside the reinforcement core when the ties are bent in to the concrete core [5]. Further, the presence of steel or polypropylene fibers and the type of aggregate in concrete influence the extent of spalling [7].

Based on the above observations, the following guidelines were incorporate into the model to determine the extent of spalling.

1. Spalling occur when the temperatures in an element exceed $350^{\circ} \mathrm{C}$.

2. Spalling is influenced by the tie configuration adopted for the column.

- Spalling occurs throughout the cross-section when the ties are bent in a conventional pattern.

- Spalling occurs only outside the reinforcement cage when the ties are bent at $135^{\circ}$ into the concrete core. 
3. The extent of spalling is dependent on the type of aggregate, presence of fiber reinforcement and spacing of ties.

- The extent of spalling is higher $(100 \%)$ in the siliceous aggregate HSC than that for carbonate aggregate HSC (40\%).

- No spalling occurs when polypropylene fibers are present in the concrete mix.

- The extent of spalling in the core of HPC with steel fiber is about $50 \%$.

- No spalling occurs inside the reinforcement core when the tie spacing is 0.7 times the standard spacing.

- The extent of spalling is also influenced by relative humidity. A higher relative humidity ( $90 \%$ of higher) leads to higher spalling.

The above guideline has been incorporated into the computer program and the user can select the extent of spalling based on the design parameters. These sets of rules are checked for each element of the network. As an illustration, when the temperature exceeds $350^{\circ} \mathrm{C}$, spalling is said to occur in that element, and the contribution of that element to strength is zero.

\section{Assumptions}

The following assumptions are made in the strength calculations:

1. The curvature of the column varies from pin ends to mid-height according to a straight-line relation.

2. Plane sections remain plane.

3. Concrete has no tensile strength.

4. There is no slip between steel and concrete.

5. The reduction in column length before exposure to fire, consisting of free shrinkage of the concrete, creep, and shortening of the column due to load, is negligible. This reduction can be eliminated by selecting the length of the shortened column as the initial length from which the changes during exposure to fire are determined.

6. The contribution of any element to strength depends on the extent of spalling in that element.

Based on the above assumptions, the column strength during exposure to fire was calculated. Because the strains and stresses in the elements are not symmetrical with respect to the y-axis, the calculations were performed for both the network shown and for an identical network to the left of the y-axis. The load that the column can carry and the moments in the section were obtained by adding the loads carried by each element and the moments contributed by them.

\section{COMPUTER IMPLEMENTATION}

\section{Computer Program}

The numerical procedure described above was incorporated into a computer program, written in Fortran language. For any time step, the analysis starts with the calculation of temperatures due to fire. The next stage is to determine the cross-sectional temperatures by making use of the thermal properties of the column materials. In the third stage, the strength of the column, during exposure to fire, is determined by successive iterations of the axial strain and curvature until the internal moment at mid-height is in equilibrium 
with the applied moment. The extent of spalling in the section is accounted for based on the above set of guidelines.

For any given curvature and, therefore for any given deflection at mid-height, the axial strain is varied until the internal moment at the mid-section is in equilibrium with the applied moment given by the product:

$$
\text { load } \times(\text { deflection }+ \text { eccentricity })
$$

In this way, a load deflection curve can be calculated for specific times during the exposure to fire. From these curves, the strength of the column, i.e., the maximum load that the column can carry, can be determined for each time step. When the equilibrium condition is satisfied, the iteration for curvature is continued in order to make sure that the point at which the equilibrium is achieved corresponds to the maximum load condition.

The fire resistance of the column is derived by calculating the strength of the column as a function of the time of exposure to fire. This strength reduces gradually with time. The time increments continue until a certain point at which the strength becomes so low that it is no longer sufficient to support the load. At this point, the column becomes unstable and is assumed to have failed. The time to reach this failure point is the fire resistance of the column.

\section{Material Properties}

Concrete: The fire resistance behavior of HPC columns is influenced by the concrete strength and the type of aggregate present in the concrete. The user has the option of selecting either NSC or HSC and siliceous aggregate concrete or carbonate aggregate concrete. Relevant formulas for the thermal and mechanical properties of HPC concrete as a function of temperature in the range of $0-1000^{\circ} \mathrm{C}$, are taken from References 16 and 17. The stress-strain curves for the concrete, expressed as a function of temperature are built into the computer program. While the presence of fibers has little influence on the thermal properties, they may have some influence on the mechanical and deformation properties. However, due to lack of data of these properties for fiber reinforced HPC, the program uses the properties of HSC for all HPC columns.

In the input data file, the user has to specify the 28-day compressive strength of the concrete, the initial moisture content in the concrete and the type of aggregate in the concrete. The initial moisture content of the column is expressed as the volume of water per cubic meter of concrete.

Steel Reinforcement: Similar to concrete, the thermal and mechanical properties of reinforcing steel are incorporated into the program and are given in the ASCE Manual [18]. The only material property the user has to specify, within the data file, is the yield strength of the reinforcement bars.

Water: The values of the thermal capacity of water and the heat of vaporization, which were used in calculating the moisture vaporization when the temperature reaches $100^{\circ} \mathrm{C}$, are also built into the computer program. The emmissivity and convection coefficients given in References 13 and 14 are used in the analysis. 


\section{RESULTS AND DISCUSSION}

Using the numerical model described in this paper, the temperatures, the axial deformations and the fire resistance were calculated for the four HPC columns given in Table 1. In the calculations, the thermal and mechanical properties of the concrete and

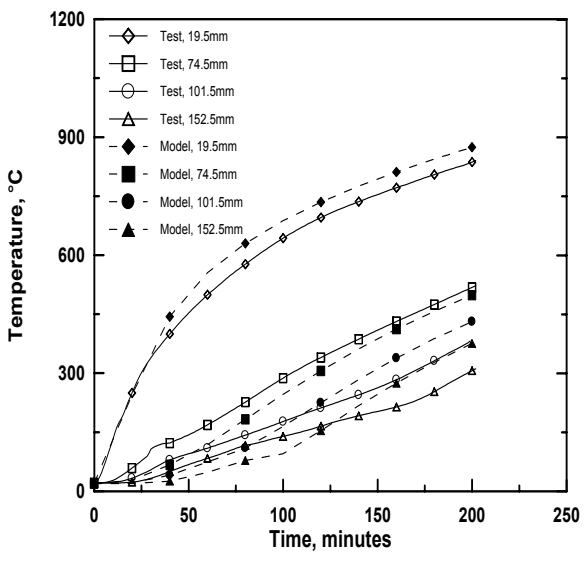

THS11

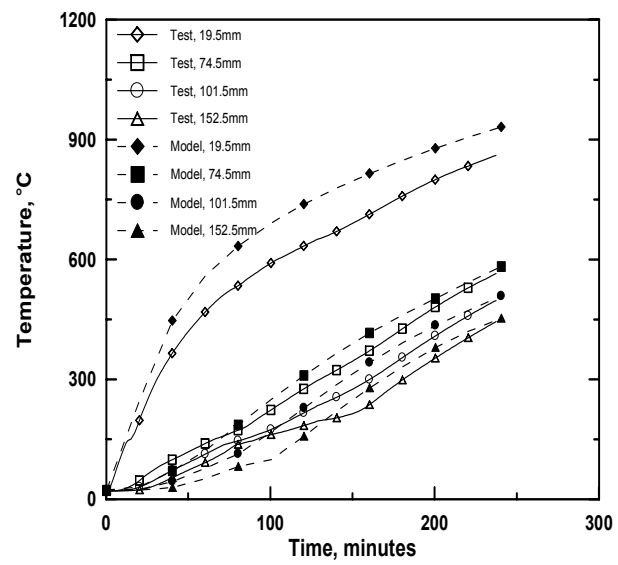

(b) Column

Figure 2 Comparison of temperature distribution at various depths for HPC columns

steel, given in the References 16 and 17, were used.

The results obtained from the computer program can be used to trace the response of an $\mathrm{RC}$ column from the initial pre-loading stage to the collapse. In the following, calculated temperatures and axial deformations of the columns will be compared with the measured temperatures and axial deformations from full-scale fire resistance tests of HPC columns THC4 and THS11. RC column THC4 is made of plain HSC, while RC column THS11 is made of steel fiber reinforced HSC. The comparison is carried out for only two columns, due to space limitations. However, the fire resistances for all four HPC columns are compared in Table 1.

\section{Temperature History}

In Figure 2, calculated temperatures are compared with those measured at various depths for columns THC4 and THS11. It can be seen that there is good agreement between calculated and measured temperatures. The temperatures measured at the center of the columns show initially a relatively rapid rise in temperature, followed by a period of nearly constant temperatures in the early stages of the test. This temperature behavior may be the result of thermally-induced migration of the moisture towards the center of the column where, as shown in the figures, the influence of migration is most pronounced [13]. Although the model takes into account evaporation of moisture, it does not take into account the migration of the moisture towards the center. That migration appears to account for the deviation between calculated and measured temperatures at the earlier stages of fire exposure. At later stages, which are important from the point of view of predicting fire resistance of columns, there is good agreement between calculated 
and measured temperatures. Similar observations were found for the other two columns THC8 and THP14.

\section{Axial Deformations}

In Figure 3, the calculated and measured axial deformations are shown for columns THC4 and THS11. It can be seen that the computer model predicts reasonably well, the trend in the progression of the axial deformations with time. However, the variation between predicted and measured deformations could be partly attributed to the "spalling factor" assumed in the analysis since the extent of spalling used in the analysis has a moderate influence on the axial deformations. To illustrate the sensitivity of the extent of spalling on axial deformations, the analysis was carried out for two cases for column THC4, namely, with $100 \%$ spalling and with $50 \%$ spalling. It can be seen in Figure 3(a) that the difference between the predicted and measured deformations reduces considerably when $50 \%$ spalling factor is assumed.

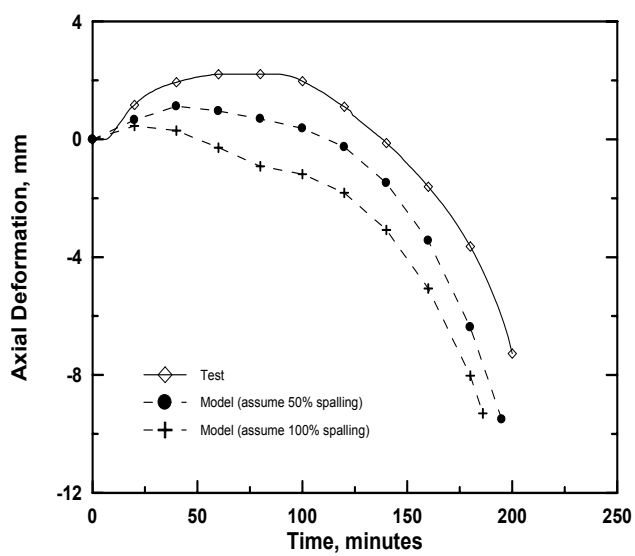

(a) Column THC4

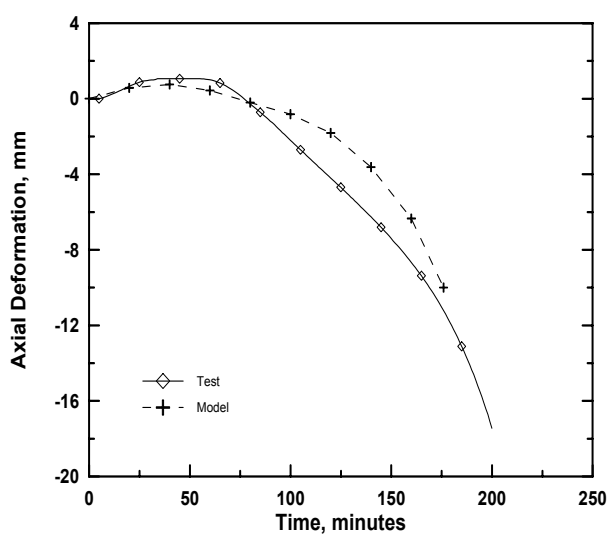

(b) Column THS11

Figure 3 Comparison of axial deformation for HPC columns

The difference between calculated and measured axial deformations at the expansion stage are on the order of $2 \mathrm{~mm}$, which may be regarded as small compared to the length of the column of about $3800 \mathrm{~mm}$. For column THC4, in the descending portion of the axial deformation curve, the predicted deformations are larger than the measured deformations and this could again be attributed to the conservative assumption of higher "spalling factor". As can be seen in the figure, when the spalling factor of $50 \%$ is assured the difference between measured and predicted deformation reduces.

In column THS11, the presence of steel fibers has some influence of mechanical and deformation properties and this could not accounted for in the analysis due to lack of data on material properties of fiber reinforced HPC at elevated temperature. Further, it must also be noted that the columns deform axially as a result of several factors, namely, load, thermal expansion, bending and the effect of creep, which is significant in later stages of fire exposure and cannot be completely taken into account in the calculations. The axial deformation predictions for columns THC8 and THP14 followed similar trend. 


\section{Fire Resistance}

The measured and predicted fire resistances of four HPC columns are compared in Table 1. The time to reach failure is defined as the fire resistance for the column. For plain HSC columns, THC4 and THC 8 , the measured fire resistance were 202 and 305 minutes, while the predicted fire resistance were 186 and 271 minutes, respectively. The predicted fire resistances are within $10 \%$ of the measured values, thus indicating that the predictions from the model are conservative.

For column THS11 the measured fire resistance was 206 min while the predicted fire resistance was 176 minutes. This high variation could be attributed to the contribution of steel fiber to strength that is not accounted for in the model. For column THP14 the measured and calculated fire resistances were 233 and 183 minutes, respectively. In this column also the presence of polypropylene fibers provided confinement to the section (at low temperatures) and enhanced fire resistance slightly. This could not be accounted for in the model due to the lack of data on the properties of fiber reinforced HPC at elevated temperature.

The predicted fire resistance from the computer program is within $10 \%$ of the measured value for plain HPC and within $20 \%$ for fibre reinforced HPC column and this is adequate for practical purposes. The larger variation between predicted and measured fire resistance is due to the use of conservative spalling factor and also due to not accounting for the contribution of fibers to strength. The accuracy of the predictions from the model can be enhanced provided the relevant material properties of fiber reinforced HPC are incorporated in to the model.

\section{CONCLUSIONS}

Based on the results of this study, the following conclusions can be drawn:

1. The computer program presented in this study is capable of predicting the fire resistance of HPC columns exposed standard fires, with an accuracy that is adequate for practical purposes.

2. The numerical model accounts for spalling of HPC under fire conditions. The simplified approach used for calculating spalling accounts for tie configuration, aggregate type and presence of fibers.

3. Using the model, the fire resistance of HPC columns, similar to those presented in the paper, can be estimated for any value of the significant parameters, such as load, section dimensions, column length, concrete strength, aggregate type and fiber reinforcement, without the necessity of testing.

4. The model can also be used for estimating the fire resistance of columns other than those investigated in this study; for example, lightweight aggregate concrete or rectangular cross-section, if the relevant material properties are known.

5. Data on the mechanical and deformation properties of fiber reinforced HPC is needed for accurately predicting the fire resistance of HPC columns.

\section{REFERENCES}


1. National Building Code of Canada 1995. National Research Council of Canada, Ottawa, ON.

2. Canadian Standards Association, Code for the Design of Concrete Structures for Buildings. CAN3-A23.3-M94, Rexdale, ON, 1994.

3. ACI Committee 318, "Building Code Requirements for Reinforced Concrete" (ACI 318-95), American Concrete Institute, Detroit, 1995.

4. Diederichs, U., Jumppanen, U.M. and Schneider, U., High Temperature Properties and Spalling Behaviour of High Strength Concrete. Proceedings of Fourth Weimar Workshop on High Performance Concrete, HAB Weimar, Germany, pp. 219-235, 1995.

5. Kodur, V.K.R. and McGrath, R., Performance of High Strength Concrete Columns under Severe Fire Conditions. Proceedings Third International Conference on Concrete under Severe Conditions, Vancouver, BC, Canada, pp. 254-268, 2001.

6. Phan, L.T., Fire Performance of High-Strength Concrete: A Report of the State-ofthe-Art. National Institute of Standards and Technology, Gaithersburg, MD, 1996.

7. Kodur, V.K.R., Cheng, F.P. and Wang T.C., Effect of strength and Fiber Reinforcement on the Fire Resistance of High Strength Concrete Columns, ASCE Journal of Structural Engineering, in press, 2002.

8. Kodur, V.K.R., "Spalling in high strength concrete exposed to fire-concerns, causes, critical parameters and cures", ASCE Structures Congress, 2001.

9. Lie, T. T., New Facility to Determine Fire Resistance of Columns. Canadian Journal of Civil Engineering, Vol. 7, No. 3, pp. 551-558, 1980.

10. Lie, T. T., and Woollerton, J. L., Fire Resistance of Reinforced Concrete Columns: Test Results. Institute for Research in Construction Internal Report No. 569, National Research Council of Canada, Ottawa, ON, 302 pp, 1988.

11. American Society for Testing and Materials, Standard Methods of Fire Endurance Tests of Building Construction and Materials. ASTM E119, Philadelphia, PA, 1990.

12. Underwriters' Laboratories of Canada, Standard Methods of Fire Endurance Tests of Building Construction and Materials".CAN/ULC-S101, Scarborough, Canada, 1989.

13. Lie, T.T and Irwin, R.J. 1993. Method to Calculate Fire Resistance of Reinforced Concrete Columns with Rectangular Cross Section. ACI St. Journal. (90) 1, 52-60.

14. Kodur, V.K.R. and Lie, T.T., A Computer Program to Calculate the Fire Resistance of Rectangular Reinforced Concrete Columns. Third Canadian Conference on Computing in Civil and Building Engineering, Ottawa, Canada, pp. 11-20, 1996.

15. Dusinberre, G. M., Heat Transfer Calculations by Finite Differences, International Textbook Company, Scranton, 1961, 293 pp.

16. Kodur, V.K.R. and Mohamed Sultan, Thermal Properties of High Strength Concrete at Elevated Temperatures. CANMET-ACI-JCI International Conference on Recent Advances in Concrete Technology, pp. 467-480, Tokushima, Japan, 1998.

17. Cheng, F.P., Kodur, V.K.R. and Wang T.C., Stress-strain Curves for High Strength Concrete at Elevated Temperatures, ASCE J of Structural Engg., 2002, (in press).

18. Lie, T.T., Ed. 1992. Structural Fire Protection, Manuals and Reports on Engineering Practice, No. 78. ASCE, New York, NY. 